\title{
A ESCRITA DE ARTIGO ACADÊMICO NA UNIVERSIDADE: AUTORIA X PLÁGIO
}

\author{
Maria Fátima Alves* \\ Universidade Federal de Campina Grande \\ Campina Grande, Paraíba, BR \\ Lucielma de Oliveira Batista Magalhães de Moura* \\ Universidade Federal de Campina Grande \\ Campina Grande, Paraíba, BR
}

\begin{abstract}
Resumo
Diante da exigência para produzir textos específicos do discurso acadêmico na universidade, muitos graduandos o fazem por meio de cópia de textos já publicados. Observamos neste trabalho a presença do plágio versus as marcas de autoria na introdução de artigos acadêmicos produzidos por graduandos iniciantes, em um Curso de Licenciatura. Para tanto, destacamos a questão do plágio e da autoria, notadamente a partir dos estudos enunciativos bakhtinianos e, em seguida, apresentamos a base teórica dos Letramentos - com foco corrente dos Novos Estudos dos Letramentos - e da Sociorretórica. A análise dos dados evidenciou e ratificou a escrita acadêmica como uma atividade complexa, dada a prática do plágio constatada nas produções analisadas. A falta de domínio da escrita acadêmica aliada ao não domínio do tema concorreram para que ocorresse a prática do plágio.
\end{abstract}

Palavras-chave: Escrita Acadêmica; Plágio; Autoria; Letramento.

\section{WRITING A RESEARCH PAPER AT THE UNIVERSITY: AUTHORSHIP VS PLAGIARISM}

\begin{abstract}
Considering the need of producing academic texts at the university, many undergraduate students do it by copying texts that were already published. In this study we discuss the presence of plagiarism versus authorship marks in the introduction of academic articles produced by freshmen in a licenciateship degree. Therefore, we emphasize the issue of plagiarism and authorship, particularly from the perspective of the enunciative Bakhtinian studies and then present the theoretical basis of Literacies, with the most recent studies on Literacies and Socio-Rhetorics. Data analysis revealed and confirmed academic writing as a complex activity, given the practice of plagiarism found in the analyzed productions. The lack of knowledge of academic writing and of the subject matter itself contributed to the practice of plagiarism.
\end{abstract}

Keywords: Academic Writing; Plagiarism; Authorship; Literacy.

\footnotetext{
Doutora em Linguistica pela Universidade Federal de Pernambuco e professora da Unidade Acadêmica de Educação da Universidade Federal de Campina Grande. Também atua como professora no Programa de Pós-graduação em Linguagem e Ensino e desenvolve pesquisas voltadas para diversos temas no âmbito da Linguistica Aplicada: leitura, escrita, gêneros textuais e letramento acadêmico. Seu endereço de email é mfatimaalves@uol.com.br

${ }^{*}$ Mestre em Linguagem e Ensino pela Universidade Federal de Campina Grande (2015); Especialista em Princípios Organizacionais da Língua e Funcionamento Textual-Discursivo pela Universidade Estadual da Paraíba (2014); Graduada em Letras-Língua Portuguesa pela Universidade Federal de Campina Grande (2011). Tem desenvolvido estudos vinculados à Linguística Aplicada com ênfase no tema de escrita, especificamente a escrita de gêneros acadêmicos na perspectiva da Sociorretórica e dos Novos Estudos dos Letramentos; ensino de Português como língua materna e formação de professores de Português. Seu endereço de email é lucielmaobmm@gmail.com
} 


\section{Introdução}

A escrita no contexto acadêmico tem sido observada e reconhecida como uma atividade complexa, dada a sua especificidade, bem como dentro da perspectiva dos novos estudos dos letramentos, como uma prática situada, a partir da qual o simples ingresso do graduando em curso de nível superior não é suficiente para a apropriação e o domínio dos gêneros que circulam nessa esfera. São exigidos outros letramentos, o que implica a adaptação a novas formas de saber: novas maneiras de compreender, interpretar e organizar o conhecimento (Cf. LEA; STREET, 1998, p. 158).

Fato comum na universidade é a exigência da produção de gêneros acadêmicos, seja para livre produção, visando à socialização de conhecimentos, seja para comprovação de produtividade, seja para verificação de aprendizagem. Ocorre que, muitas vezes, os graduandos, inclusive iniciantes, são solicitados a escrever textos acadêmicos - a exemplo do artigo científico - e, ao escrever seu texto, o fazem por meio de cópia de textos já publicados, aspecto que se apresenta bastante preocupante.

Sob esse viés, a escrita no contexto acadêmico pode ser observada como locus de tensão entre a necessidade de cumprimento de atividades de escrita do discurso científico dentro das disciplinas versus a produção do conhecimento a partir da elaboração de um texto que desenvolva uma linha argumentativa com traços de autoria, em defesa de um ponto de vista.

Diante dessa problemática, o foco do presente artigo situa-se justamente na observação de plágio versus marcas de autoria presentes em introduções de artigos acadêmicos produzidos por graduandos iniciantes de um Curso de Licenciatura, realizadas como atividade avaliativa relativa ao cumprimento de nota dentro de um componente curricular do referido curso.

Para tanto, realizamos uma pesquisa qualitativa, na qual destacamos algumas das especificidades da escrita acadêmica, como também a noção de plágio e de autoria a partir da contribuição de estudiosos, notadamente a partir da noção bakhtiniana de autoria. Em seguida, situamos teoricamente a perspectiva de estudos da escrita em contexto acadêmico na perspectiva dos
Ltramentos Acadêmicos e da Sociorretórica, bem como expomos o modelo de análise de introdução de artigo acadêmico proposto por Swales (1990). Por fim, apresentamos a análise das introduções, seguida das nossas considerações.

\section{Plágio e autoria na escrita acadêmica}

No contexto nacional, a escrita na academia tem despertado o interesse de diversos estudiosos, a exemplo de Bezerra (2012), Santos (2013), Oliveira (2010), Marinho (2010), Machado (2004), Silva (2012; 2014) e de Figueiredo e Bonini (2006). Esses últimos observam que durante a formação no ensino superior espera-se que os estudantes universitários adquiram a capacidade de discutir e aplicar conhecimentos teóricos adquiridos ao longo do curso (ou das disciplinas), bem como de expor suas ideias sobre determinado tema, de forma clara e convincente por meio dos gêneros acadêmicos. No entanto, o que as pesquisadoras (op. cit. 2006) percebem é que muitos alunos demonstram dificuldade na produção de trabalhos escritos, tanto no que se refere à forma do texto quanto no que diz respeito à construção de uma linha argumentativa e/ou expositiva que possibilite a exposição e a discussão clara de teorias, fatos, ideias e posições pessoais.

Soma-se às constatações supracitadas a dificuldade de articulação entre o discurso próprio e o discurso de outrem, conforme atesta Delcambre (2015). Percebese na escrita dos graduandos uma grande dificuldade em dialogar com as vozes e os discursos do outro, bem como situar-se como autor do próprio discurso.

Outro agravante em relação à produção dos gêneros acadêmicos ocorre quando a exigência da escrita especializada é dirigida a alunos iniciantes, pouco familiarizados com as práticas de leitura e de escrita do meio acadêmico. Todo esse cenário, possivelmente, conduz o aluno à prática do plágio.

Segundo Fonseca, o plágio (s.d.) caracteriza-se pela apropriação ou expropriação de direitos intelectuais. De acordo com o referido autor, o termo "plágio" vem do Latim "plagiarius", um abdutor de "plagiare", ou seja, "roubar", e trata-se da expropriação do texto de um outro autor como sendo de cunho próprio (FONSECA, s.d.). 
Há quem defenda que o acesso à rede mundial de computadores, com ambientes e espaços diversos de divulgação do conhecimento, além de fonte rica de propagação de saberes e informações, tem propiciado a prática do plágio. No mesmo contexto de discussão, a facilidade ao acesso a textos de circulação eletrônica, a rapidez, bem como a disponibilidade dos textos, dentre outras possíveis motivações, têm sido apontadas por estudiosos, a exemplo de Silva (2008), como fatores que contribuem diretamente para que o plágio ocorra:

Na busca por caminhos mais fáceis e mais velozes, e tendo como aliada a natureza aparentemente pública do conteúdo on-line, além da disponibilidade dos hipertextos digitais [...] haja vista a velocidade na transmissão das informações e a grande quantidade de textos/ obras à disposição na internet: "fica difícil não plagiar com tantas oportunidades" (GB) declara um graduando envolvido na pesquisa desenvolvida por Silva. (SILVA, 2008, p. 358, grifos nossos).

No que se refere à dificuldade encontrada pelos alunos na produção de textos acadêmicos, Silva (2008) acrescenta-nos uma reflexão muito pertinente acerca das práticas de escrita desenvolvidas ao longo dos anos escolares do alunado. A estudiosa aponta que, historicamente, os alunos têm convivido com a prática de cópia de produções textuais de outros, seja parcial ou total, com omissão da fonte (SILVA, 2008, p. 357). Assim, de acordo com a pesquisadora (op. cit., 2008), a prática do plágio que se percebe nos anos escolares de nível superior nada mais é do que um reflexo das práticas escolares que incentivaram, durante anos de escolarização, as atividades baseadas em cópia.

O posicionamento supracitado aponta a escola - o modelo de ensino que vem sendo desenvolvido - como força motriz que leva à desmedida prática do plágio, bem como percebe as atividades escolares de cópia como legitimadoras de um modo errôneo de realizar pesquisa. Desse modo, a estudiosa defende que, ao perpetuar tais práticas, a escola não está cumprindo com o seu papel de colaboradora no desenvolvimento de sujeitos críticos, reflexivos e autônomos, mas está forjando leitores e produtores de textos (SILVA, 2008). Seguindo essa linha de pensamento, é admissível pressupor que o aluno imaturo para as práticas letradas da academia esteja pensando que está realizando "pesquisa", quando, na verdade, está dando continuidade às praticas iniciadas, aceitas e valorizadas nos anos iniciais de escolarização.

Em oposição à noção de plágio, destacamos a noção de autoria, instaurada justamente a partir da produção autônoma do texto e do discurso. Tomemos a concepção de Bakhtin (2003, p. 310), o qual nos fala que cada texto - como enunciação - é algo individual, único e singular, e nisso reside todo o seu sentido, sua intenção em prol da qual ele foi criado, aspecto que nos aponta a intrínseca relação da noção bakhtiniana de autoria com a noção de enunciação.

Ainda nos termos bakhtinianos, o enunciado nunca é apenas um reflexo, uma expressão de algo já existente fora dele dado e acabado. Ele sempre cria algo que não existia antes dele, absolutamente novo e singular, e ainda por cima tem relação com o valor. (BAKHTIN, 2003, p. 326).

Coadunando com a perspectiva aqui apresentada, Sobral (2009, p. 61) acrescenta que a concepção de autoria compreende, de um lado, o princípio dialógico relação com o outro - e de outro, as relações sociais e históricas que formam o contexto da interação e que incidem sobre a ação autoral. Assim, a concepção bakhtiniana de autoria eleva o outro como instância chave para a formulação de três princípios da linguagem formulados pelo filósofo russo: o princípio dialógico, o princípio exotópico e a noção de responsividade.

O princípio dialógico da linguagem é, para Bakhtin (2002 apud COSTA, 2012), o princípio constitutivo da linguagem e a condição de sentido do discurso. Os textos são constituídos a partir de outros textos, contendo não só o discurso do próprio autor, mas também o discurso de outras pessoas, pois tudo o que é dito por um enunciador não pertence só a ele. Assim, a presença desses vários discursos, ou seja, dessas várias vozes no texto é chamada de dialogismo por Bakhtin e é compreendida como uma memória semântico-social depositada na palavra (COSTA, 2012). Ao lado do princípio dialógico da linguagem, e decorrente deste, também importante na compreensão da noção bakhtiniana de autoria, é o princípio da exotopia, segundo o qual o autor possui um excedente de visão, um olhar de fora, uma consciência 
externa que the permite visualizar sua produção a partir de uma posição privilegiada. Por fim, o princípio da responsividade diz respeito ao papel do interlocutor na compreensão/construção do sentido do texto. A construção do enunciado é dotada de uma atitude responsiva aos outros enunciados (BAKHTIN, 2003, p. 297). Assim, a compreensão do enunciado é tomada como uma atitude responsiva à construção do sentido do texto.

Desse modo, compreendemos que, além do conhecimento de aspectos estruturais, pragmáticos e retóricos, a escrita acadêmica pressupõe o domínio do aspecto discursivo - situado no nível enunciativo, o qual pressupõe uma nova produção de sentido, na qual se exige o caráter criativamente produtivo e autônomo do autor para a tomada de posições, articulação do discurso próprio com o discurso do outro e inserção da sua voz na construção e na constituição do texto. Produzir um texto autoral na universidade, na perspectiva bakhtiniana é, por assim dizer, retomar conhecimentos já produzidos, aliando-os a propósitos e objetivos definidos, a fim de produzir interpretações e conhecimentos autênticos.

\section{Perspectivas de estudo e análise do texto escrito: Novos Estudos dos Letramentos e Sociorretórica}

Duas correntes teóricas de estudo do texto escrito nortearam a pesquisa ora apresentada. A primeira delas é a perspectiva do Letramento acadêmico, notadamente, a perspectiva dos novos estudos dos letramentos, cujo foco de investigação tem se voltado para contextos específicos. A referida perspectiva parte da compreensão de que cada esfera de produção e circulação do gênero exige um letramento específico. Não diferente de outros contextos, observa-se na esfera acadêmica um conjunto específico de práticas e usos da escrita, os quais estão intimamente relacionados às formas de ação e produção próprias da comunidade discursiva científica.

Uma segunda perspectiva de estudo do texto escrito que nos serviu para análise e leitura dos artigos produzidos é a perspectiva da Sociorretórica, segundo a qual o gênero textual pode ser observado a partir das suas regularidades formais e discursivas. Adotamos o posicionamento de que o ensino explícito da escrita, aliado à transparência dos critérios relevantes na produção dos gêneros, é uma alternativa produtiva para o letramento acadêmico no processo de ensino-aprendizagem da escrita acadêmica. Desse modo, aderimos a uma perspectiva de análise retórica do texto, observando aspectos linguísticos, bem como a distribuição das informações ao longo do texto, segundo o modelo apresentado adiante.

\section{O modelo CARS: modelo de análise da in- trodução de artigos}

Dentre outras contribuições para o delineamento da área de estudo da sociorretórica, Swales (1990) apresenta um modelo teórico-metodológico de estudo do texto escrito, especificamente em contextos acadêmicos e profissionais - o modelo CARS (Create a Research Space). Tal modelo tem como base a distribuição das informações no texto a partir da observação de regularidades na composição retórica textual, especificamente com foco na análise de introduções de artigos científicos ${ }^{1}$ (BIASI- RODRIGUES; HEMAIS; ARAÚJO, 2009). A aplicação da teoria swaleana ao ensino tem oferecido subsídios para a identificação das características formais e funcionais dos gêneros, como também para o reconhecimento destes a partir dos seus propósitos comunicativos, já que são estudos que se apoiam em fenômenos linguísticos e em aspectos formais da construção do texto, sem desconsiderar as práticas sociais. Apresentamos a seguir o modelo CARS, composto por movimentos (moves) e passos (steps):

Figura 1: Estrutura retórica da introdução de artigo científico - modelo CARS

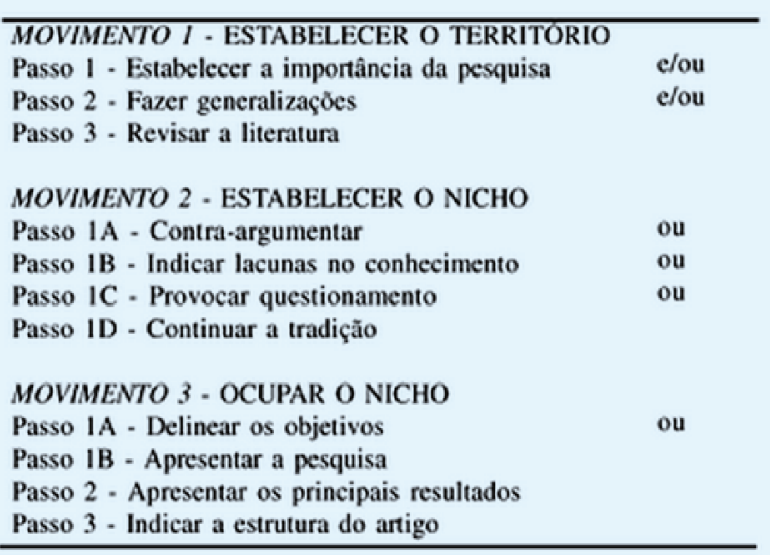

Fonte: Swales (1990) 
O movimento 1, "estabelecer o território", contempla três passos que sinalizam diferentes informações: no passo 1, o autor chama a atenção da comunidade discursiva para uma área de pesquisa significativa $\mathrm{e}$ bem estabelecida; no passo 2, o autor toma uma posição neutra e faz declarações generalizadas sobre conhecimento ou prática corrente. Por fim, no passo 3, o autor faz referência aos pesquisadores que atuaram anteriormente na área e relata o que descobriram. Vale salientar que o próprio Swales, reforçado por Biasi-Rodrigues; Hemais; Araújo (2009), alerta para o fato de que os passos não são obrigatórios e que as introduções podem não seguir a organização retórica apresentada/proposta (BIASI-RODRIGUES; HEMAIS; ARAÚJO, 2009).

O movimento 2, "estabelecer o nicho", contempla um passo dentre quatro possibilidades, a saber, (1A) contra-argumentar, (1B) indicar lacuna/s no conhecimento, (1C) indicar questionamento ou (1D) continuar tradição. Nesse movimento, tem destaque o primeiro passo, $1 \mathrm{~A}$, o qual é indicado pelo idealizador do modelo como o mais recorrente (BIASI- RODRIGUES; HEMAIS; ARAÚJO, 2009).

No movimento 3, "ocupar o nicho", como o próprio nome sugere, o autor propõe-se a ocupar o espaço de pesquisa já apontado no movimento anterior em duas opções (1A e 1B). O passo $1 \mathrm{~A}$ é destinado à apresentação dos objetivos e o passo $1 \mathrm{~B}$, à descrição das principais características da pesquisa (BIASI- RODRIGUES; HEMAIS; ARAÚJO, 2009). De acordo com o idealizador do modelo, essa disposição das informações constitui modelo prototípico para a observação/produção do artigo científico.

Feita essa discussão sobre os aspectos teóricos que nortearam o presente estudo, apresentaremos, a seguir, o cenário da metodologia utilizada para a coleta e análise dos dados.

\section{Cenário de coleta e aspectos metodológicos}

A pesquisa apresentada insere-se no paradigma não positivista e se caracteriza como investigação de natureza qualitativa, mais especificamente, como pesquisa participante com contornos etnográficos, tendo em vista que combinamos diferentes instrumentos de coleta de dados. Segundo a definição de pesquisa etnográfica de Ludke e André (1986), esta classifica-se como um método de percepção da realidade qualificada como estratégia de campo que combina simultaneamente a análise documental, a entrevista, a participação, a observação direta e a introspecção. Nossa escolha por mais de um instrumento de coleta justifica-se pela necessidade de investigar o objeto de estudo a partir de diferentes perspectivas.

Assim, para a coleta dos dados, combinamos os seguintes instrumentos: I) questionários: aplicamos questionários no início da pesquisa para sondagem do perfil social dos alunos e no final da pesquisa para identificar as dificuldades na produção do artigo; II) observação direta: acompanhamos uma turma de uma instituição de nível superior durante um semestre dentro de um componente curricular de ensino de escrita; III) análise documental: recolhemos depoimentos dos alunos quanto as suas experiências com a escrita, bem como os artigos produzidos pelos colaboradores no final da disciplina.

A presente pesquisa foi realizada em um curso de Licenciatura de uma universidade federal brasileira, durante dois períodos letivos, com 15 alunos do segundo período desse curso, do turno noturno, matriculados no componente curricular Análise e Produção de Textos acadêmicos - doravante APTA. Dentre os 15 alunos, foram selecionados três colaboradores, segundo os critérios de participação ativa nas aulas e realização de todas as atividades propostas para a composição do corpus da pesquisa. Desse modo, foram selecionadas a colaboradora A, a colaboradora B e a colaboradora C, todas do sexo feminino. No presente artigo, apresentamos a análise de duas produções, especificamente duas introduções de artigo científico, correspondentes às produções da colaboradora $\mathrm{A}$ e da colaboradora $\mathrm{B}$.

A colaboradora A, com 34 anos, na época da coleta dos dados, apresenta uma percepção da escrita como uma atividade prazerosa, ao afirmar: "escrever para mim é prazerozo $(s i c)$, me leva além, me enriquece e enobrece a alma", além de descrever participação em atividades que apontam proximidade com a escrita. A colaboradora B, com 30 anos, já formada em outro curso de licenciatura, também denota uma relação pra- 
zerosa com a escrita: "lembro-me que sempre gostei de ler e escrever, mas confesso que a escrita me fascinava porque eu me sentia leve ao redigir as palavras". As falas das colaboradoras apontam um perfil de histórico de letramento que denota uma relação de proximidade com a escrita.

Os dados coletados pelos diferentes instrumentos de coleta contribuíram para a análise de um artigo científico, correspondente à atividade proposta na unidade III dentro do componente curricular de escrita APTA. $\mathrm{Na}$ ocasião, foi solicitado que os alunos produzissem um artigo científico para compor a nota da terceira unidade. A professora fez um levantamento sobre as temáticas que os alunos gostariam de pesquisar e, por ser estudiosa da de linguística, sugeriu alguns temas a exemplo de leitura, escrita, gêneros textuais, práticas de letramento. Selecionado o tema a ser trabalhado, a docente indicou diversas referências bibliográficas de autores renomados na área e marcou alguns encontros para estudo orientado sobre a escrita do artigo, tanto no que concerne à parte formal quanto à discursiva. Ainda, a docente sugeriu que o artigo fosse de natureza bibliográfica devido ao pouco tempo que os alunos teriam para produzi-los.

O referencial teórico adotado pelo professor para o ensino do artigo científico foram os capítulos 4, 5, 6 e 7 intitulados respectivamente, "Artigo científico: introdução"; "Artigo científico: revisão da literatura", "Artigo científico: metodologia"; "Artigo científico: análise e discussão dos resultados", do livro Produção Textual na Universidade, de Desirée Motta-Roth e Graciela Habuske Hendges (2010). Seguindo a metodologia de ensino explícito para produção dos artigos científicos, adotou-se o modelo CARS, de Swales, 1990-2004, como prototípico para o ensino e análise das informações na tessitura da introdução dos artigos produzidos, compreendendo assim a observação dos níveis formal e discursivo.

Quanto aos aspectos metodológicos empregados em fase anterior à solicitação da produção escrita, foram trabalhados textos teóricos seguidos da apreciação de artigos acadêmicos publicados em revistas e periódicos da área de Linguística, de modo a favorecer a familiaridade dos alunos com o gênero estudado. $\mathrm{O}$ estudo do artigo frisou a análise da estrutura organizacional e as partes constituintes dos mesmos, além de características funcionais que foram destacadas pelo professor do componente curricular ANPT, no estudo do artigo científico.

Por envolver seres humanos, a presente pesquisa atentou para os princípios éticos estabelecidos pela Resolução 466 de dezembro de 2012 e foi submetida à apreciação do Comitê de Ética. Seguiu, ainda, as determinações quanto à entrega de Termos de Consentimento Livre e Esclarecido e quanto à preservação da identidade dos sujeitos envolvidos.

\section{Análise dos dados}

Realizamos uma análise da seção introdução do artigo científico ${ }^{2}$ observando o domínio da estrutura composicional dos textos, segundo o modelo de análise proposto por Swales (1990). Indissociavelmente à análise da estrutura organizacional, observamos a questão da autoria e os mecanismos usados na tessitura das introduções dos artigos.

\section{Produção I: colaboradora A}

De modo geral, a observação do artigo da colaboradora A na íntegra permitiu-nos perceber o emprego adequado da modalidade escrita formal da língua, o desenvolvimento de uma argumentação consistente e uma progressão textual fluente, superando inclusive as expectativas para um aluno de segundo semestre, iniciante nas práticas de escrita acadêmica. Do ponto de vista composicional, o artigo foi desenvolvido em dez laudas, composto por uma estrutura organizacional a contento - título, nome do autor, resumo, palavras-chave, introdução, fundamentação teórica, considerações finais e referências.

Com relação à estrutura retórica composicional da introdução, verificamos que a colaboradora A construiu os movimentos e passos observados e propostos por Swales (1990), conforme texto e análise dos movimentos apresentados a seguir: 
Figura 2: Estrutura retórica da introdução do artigo da colaboradora A:

\section{1- INTRODUCÃO}

A leitura é essencial na educação do individuo. No entanto, o hábito de ler do aluno brasileiro ainda é um grande ponto de interrogação.

Nos Estados Unidos entre os anos de 1975 e 1977 foram publicadas 1.588 pesquisas voltadas para a área de leitura vinculada somente em uma revista especializada (SILVA, 2005). No Brasil, apesar de serem comuns os comentários sobre o problema da leitura, não se tem uma verdadeira dimensăo deste problema, isso porque não hả pesquisas publicadas em número suficiente sobre este tema, e as que existem, na maior parte das vezes, se referem á educaçầo básica. No nivel universitário, no qual há uma insatisfação geral dos professores em relação à leitura por parte dos seus alunos, ainda não existem pesquisas significativas que mostrem a natureza do aluno leitor.

Apesar dos poucos dados encontrados, podemos afirmar que o estudante acadêmico no país, em sua maioria, despreza a leitura como fonte de entretenimento, informaçăo e crescimento pessoal, limitando-se, na maior parte das ocasices, a apenas ler aquilo que é obrigado por necessidade das disciplinas cursadas, como atividades, apostilas e livros passados pelos professores. Ou seja, mesmo dominando os rudimentos da leitura e da escrita. e sendo cabazes de entender un texto de forma razó́vel. possuindo um nivel de escolarizaça acima da média, essas pessoas nâto costumam praticat a leitura.

O reflexo dessa realidade do povo brasileiro se projeta na educaçăo, desde a estrutura familiar, passando pelo ensino fundamental e estendendo-se até a universidade.

É diante de tantos questionamentos sobre a atual situaçào a respeito da leitura, do pouco interesse ou da falta de incentivo as pesquisas sobre o tema, principalmente entre as instituiģbes de ensino superior, que se toma importante um aprofundamento em relaçào a essa problemática, o pouco hábito da leitura por parte dos estudantes universitários.

Tais inquietaçōes referentes à leitura provém da crença de que um bom leitor pode criar melhores condiç̋es para a điversificaçào $\mathrm{e}$ ampliaçăo das informaçðes que săo veiculadas a ele. Saber ler é uma exigéncia das sociedades modernas. Há uma importante diferença entre saber ler e praticar efetivamente a leitura: se aquela é uma necessidade formal e permite a realizaçào individual de atividades básicas, como executar tarefas cotidianas, a esta é um importante instrumento para o exercicio da cidadania e mara a inclusto social do individuo.

Diante deste contexto, este antigo tem como objetivo realizar uma reflexho a respeito da compreenșio da leitura por alunos na academia. para isto, foi realizado uma pesquisa bibliogrifica.
M1: Estabeler o

territónio

Passo 2: Fazer

generalizaçoes

M2: Estabelecer

nincho

Passo 1B: Indicar

lacunas no

conhecimento

M1: Estabelecer o terrtório

Passo 3: Rerisar a literatura

M1: Estabelecer o

nincho

Passo 1B: Indicar

lacunas no

conhecimento

M1: Estabelecer o território

Passo 3: Revisar a literatura

M3: Ocupar o

nincho

Passo 1A:

Delinear os objetivos

Fonte: Introdução do artigo científico apresentado pela co-

laboradora A 
Uma análise atenta do texto apresentado permite-nos perceber que este foi constituído, em sua maior parte, de cópia de um artigo. ${ }^{3} \mathrm{~A}$ introdução original encontra-se no artigo "Refletindo sobre a dificuldade de leitura em alunos do ensino superior: 'deficiência' ou simples falta de hábito?", de Cleber Tourinho (2011), publicado em revista digital de circulação eletrônica.

A colaboradora A demonstra um cuidado na tessitura do seu texto modificando o texto plagiado com uso de mecanismos linguísticos e estruturais, possivelmente para que o texto pareça ser de sua autoria, deixando o texto mais adequado ao nível vocabular; à temática abordada; e/ou à estrutura retórica composicional da introdução de artigos - estudada no próprio componente curricular durante o qual o artigo foi solicitado.

A seguir, apresentamos a comparação dos fragmentos presentes na introdução da colaboradora $\mathrm{A}$, (em cor rosa), seguido do texto original, (em cor azul), com atenção aos mecanismos usados pela autora na tessitura da introdução - apagamento de termos e /ou ideias; substituição de termos ou elementos coesivos e ajustes; inclusão de termos; trechos autorais e indicação da posição do apagamento - conforme cores indicadas na legenda da tabela a seguir:

Tabela 1: Legenda - Mecanismos usados na tessitura da introdução

\begin{tabular}{|l|}
\hline Apagamento de termos e/ou ideias \\
Substituição de termos/ elementos coesivos e ajustes \\
\hline Inclusão de termos \\
Trechos autorais \\
Posição do apagamento \\
\hline
\end{tabular}

Fonte: Elaborada pela autora (2015)

Figura 3: Autoria x plágio: Introdução artigo científico da colaboradora A

\section{1- INTRODUÇÃo}

A leitura énessencial na educação do individuo. No entanto, o hábito de ler do aluno brasileiro ainda é um grande ponto de interrogaçăon Nos Estados Unidos entre os anos de 1975 e 1977 foram publicadas 1.588 pesquisas voltadas para a área de leitura vinculada somente em uma revista especializada (SILVA, 2005). No Brasil, apesar de serem comuns os comentários sobre o problema da leitura, nåo se tem uma verdadeira dimensão deste problema, isso porque não há pesquisas publicadas em número suficiente sobre este tema, $\mathrm{e}$ as que existem, na maior parte das vezes, se referem à educaçâo básica. „No nivel universitário, no qual hả uma insatisfacấo zeral dos professores em relaçăo a leitura por parte dos seus alunos, ainda năo existem pesquisas significativas que mostrem a natureza do aluno leitors

\section{INTRODUÇÄO}

A leitura é vista como parte essencial na educação do individuo. No entanto, 0 hábito de ler do aluno brasileiro é um grande ponto de interrogaçăo. So nos Estados Unidos entre 1975 e 1977 foram publicadas 1.588 pesquisas voltadas para a área de leitura vinculada somente em uma revista especializada (SILVA, 2005). No Brasil, apesar de serem comuns os comentarios sobre a crise da leitura que atravessa o pais, nåo se tem uma verdadeira dimensăo deste problema, simplesmente porque năo há pesquisas publicadas em número suficiente sobre este tema, e as que existem, na maior parte das vezes, são referentes á alfabetização. Após a inclusăo da redaçåo no vestibular, surgiram alguns estudos, mas apenas no âmbito da escrita. No nivel universitario, no qual hà uma insatistaçăo geral dos professores em relaçăo à leitura por parte dos seus alunos, ainda năo exisțem pesquisas significativas que mostrem a natureza do aluno-leitor ou dos livros a eles abresentados.

- Apesar dos poucos dados encontrados, podemos afirmar que on estudante acadèmico no pais, em sua maioria, despreza a leitura como fonte de entretenimento, informaçăo e crescimento pessoal, limitando-se, na maior parte das ocasiōes, a apenas ler aquilo que é obrigado por necessidade das disciplinas cursadas, como atividades, apostilas e livros passados pelos professores, Ou seja, mesmo dominando os rudimentos da leitura e da escrita, e sendo capazes de entender un texto de forma razoável, possuindo um nivel de escolarização acima da média, essas pessoas não costumam praticar a leitura.

Năo obstante, apesar dos poucos dados encontrados, pode-se afirmar com segurança que 0 atual estudante de nivel universitário no pais, em sua maioria, despreza a leitura como fonte de entretenimento, informação e crescimento pessoal, limitando-se, na maior parte das ocasioes, a apenas ler aquilo que é obrigado por necessidade das disciplinas cursadas, como atividades, apostilas e livros passados pelos professores. Ou seja, mesmo dominando os rudimentos da leitura e da escrita, e sendo capazes de entender um texto de forma razoável, possuindo um nivel de escolarizaçăo acima da média, essas pessoas năo se sentem bem em praticar a leitura. Passam, por isso, ao largo do que se considera Alfabetizaçăo Funcional ${ }^{2}$.

Tais inquietaçốes referentes à leitura provêm da crença de que um bom leitor pode criar melhores condiçōes para a diversificaçăo e ampliação das informaçōes que săo veiculadas a ele. Saber ler é uma exigència das sociedades modernas. Háı uma importante diferença entre saber ler e praticar efetivamente a leitura: se aquela é uma necessidade formal e permite a realizaçào individual de atividades básicas, como executar tarefas cotidianas, a esta é um importante instrumento para o exercicio da cidadania e para a inclusão social do individuo. Diante deste contexto, este artigo tem como objetivo realizar uma reflexão a respeito da compreensảo da leitura por alunos na academia, para isto, foi realizado uma pesquisa bibliográfica.

Tais inquietaçôes relativas ao tema advêm da crença de que um bom leitor pode criar melhores condiçōes para a diversificaçăo e ampliaçăo das informaçōes que såo veiculadas a ele. Saber ler é uma exigència das sociedades modernas. Há, porém, uma importante diferença entre saber ler e praticar efetivamente a leitura: se aquela $e$ uma necessidade pragmatica e permite a realização individual de atividades básicas, como executar tarefas cotidianas, a esta ef um importante instrumento para o exercicio da cidadania e para a inclusăo social do individuo.

Fonte: Introdução artigo científico da Colaboradora A; texto original (Tourinho, 2011) 
Figura 4: Autoria x plágio: Introdução artigo científico da colaboradora A

\section{INTRODUCC̃o}

A leitura éressencial na educação do individuo. No entanto, o habito de ler do aluno brasileiro ainda é um grande ponto de interrogaçãos Nos Estados Unidos entre os anos de 1975 e 1977 foram publicadas 1.588 pesquisas voltadas para a área de leitura vinculada somente em uma revista especializada (SILVA, 2005). No Brasil, apesar de serem comuns os comentários sobre o problema da leitura, nåo se tem uma verdadeira dimensão deste problema, isso porque não há pesquisas publicadas em número suficiente sobre este tema, e as que existem, na maior parte das vezes, se referem à educaçâo básica. „No nivel universitário, no qual há uma insatisfacâo zeral dos professores em relaçăo à leitura por parte dos seus alunos, ainda nà̀o existem pesquisas significativas que mostrem a natureza do aluno leitors

\section{INTRODUCCÃO}

A leitura é vista como parte essencial na educação do individuo. No entanto, 0 habito de ler do aluno brasileiro é um grande ponto de interrogaçăo. So nos Estados Unidos entre 1975 e 1977 foram publicadas 1.588 pesquisas voltadas para a área de leitura vinculada somente em uma revista especializada (SILVA, 2005). No Brasil, apesar de serem comuns os comentarios sobre a crise da leitura que atravessa o pais, năo se tem uma verdadeira dimensăo deste problema, simplesmentê porque nảo há pesquisas publicadas em número suficiente sobre este tema, e as que existem, na maior parte das vezes, são referentes á alfabetizaçåo. Após a inclusăo da redaçăo no vestibular, surgiram alguns estudos, mas apenas no âmbito da escrita. No nivel universitario, no qual há uma insatisfacăo geral dos professores em relaçăo a leitura por parte dos seus alunos, ainda năo existem pesquisas significativas que mostrem a natureza do aluno-leitor ou dos livros a eles apresentados.

- Apesar dos poucos dados encontrados, podemos afirmar que on estudante acadèmico no pais, em sua maioria, despreza a leitura como fonte de entretenimento, informaçăo e crescimento pessoal, limitando-se, na maior parte das ocasióes, a apenas ler aquilo que é obrigado por necessidade das disciplinas cursadas, como atividades, apostilas e livros passados pelos professores, Ou seja, mesmo dominando os rudimentos da leitura e da escrita, e sendo capazes de entender un texto de forma razoável, possuindo um nivel de escolarização acima da média, essas pessoas não costumam praticar a leitura.x

Năo obstante, apesar dos poucos dados encontrados, pode-se afirmar com segurança que 0 atual estudante de nivel universitario no pais, em sua maioria, despreza a leitura como fonte de entretenimento, informação e crescimento pessoal, limitando-se, na maior parte das ocasioes, a apenas ler aquilo que é obrigado por necessidade das disciplinas cursadas, como atividades, apostilas e livros passados pelos professores. Ou seja, mesmo dominando os rudimentos da leitura e da escrita, e sendo capazes de entender um texto de forma razoável, possuindo um nivel de escolarizaçåo acima da média, essas pessoas năo se sentem bem em praticar a leitura. Passam, por isso, ao largo do que se considera Alfabetizaçåo Funcional ${ }^{2}$.

O reflexo dessa realidadendo povo brasileiro se projeta na educaçăo, desde a estrutura familiar, passando pelo ensino fundamental e estendendo-se até a universidade. É diante de tantos questionamentos sobre a atual situacăo a respeito da leitura, do pouco interesse ou da falta de incentivo às pesquisas sobre o tema. principalmente entre astinstituições de ensino superior, que se torna importante um aprofundamento em relação a essa problemática, onpouco hábito da leituraspor parte dos estudantes universitários.

a reflexo dessa realidade historica do povo brasileiro se projeta na educaçăo desde a estrutura familiar, passando pelo Ensino Fundamental e estendendo-se até - Ensino Superior. E diante de tantos questionamentos sobre a atual conjuntura a respeito da leitura, do pouco interesse ou da falta de incentivo as pesquisas sobre 0 tema, principalmente entre as próprias Instituiçoes de Ensino Superior, que se torna vital um aprofundamento em relaçăo a perspectiva de ser esta uma "deficiência" ou. caso seja necessário se utilizar de outro expediente terminológico, o simples pouco habito da leitura (algo volitivo) por parte dos estudantes universitarios.
Tais inquietaçốes referentes à leitura provêm da crença de que um bom leitor pode criar melhores condiçð̌es para a diversificaçåo e ampliaçåo das informaçōes que são veiculadas a ele. Saber ler é uma exigència das sociedades modernas. Háı uma importante diferença entre saber ler e praticar efetivamente a leitura: se aquela é uma necessidade formal e permite a realização individual de atividades básicas, como executar tarefas cotidianas, a esta é um importante instrumento para o exercicio da cidadania e para a inclusão social do individuo. Diante deste contexto, este artigo tem como objetivo realizar uma reflexão a respeito da compreensăo da leitura por alunos na academia, para isto, foi realizado uma pesquisa bibliográfica.

Tais inquietaçōes relativas ao tema advêm da crença de que um bom leitor pode criar melhores condiçōes para a diversificaçăo e ampliaçăo das informaçđè que săo veiculadas a ele. Saber ler é uma exigencia das sociedades modernas. Ha, porém, uma importante diferença entre saber ler e praticar efetivamente a leitura: se aquela e uma necessidade pragmatica e permite a realizaçăo individual de atividades básicas, como executar tarefas cotidianas, a esta e um importante instrumento para o exercicio da cidadania e para a inclusăo social do individuo.

Fonte: Introdução artigo científico da Colaboradora A; texto original (Tourinho, 2011)

Logo no parágrafo introdutório são perceptíveis ações como: I) apagamento do termo modalizador " vista como parte" (L.1), da partícula restritiva "só" (L. 2), e de fragmentos textuais desconectados com o tema da colaboradora A, como "Após a inclusão da redação no vestibular", "surgiram alguns estudos, mas apenas no âmbito da escrita". (L. 8 a 10) e "ou dois livros a eles apresentados" (L.12 a 13); II) substituição de expressões: " $a$ crise" por "o problema", "simplesmente" por "isso", "são referentes" por "se referem" e "alfabetização" por "educação básica"; e III) inclusão de termos, como o adjunto adverbial "ainda" (L. 2).

No segundo parágrafo, repetem-se ações e/ou mecanismos linguísticos e organizacionais apresentados no parágrafo inicial - (I) apagamento do elemento coesivo "não obstante" (L. 1), do adjunto adverbial de modo "com segurança" (L. 2), e do adjunto adnominal "atual" (L. 2); (II) Substituição de termos como "de nível universitário" por "acadêmico" (L.2) e "se sentem bem" por “costumam" (L.7).

Dentre os mecanismos presentes no parágrafo 3 , já destacados nos parágrafos anteriores, o que merece destaque é a substituição do termo "conjuntura" por "situação" (L. 3) e o apagamento da expressão "algo volitivo" (L. 8). Ambas as estratégias corroboram a simplificação dos termos empregados e/ou nivelamento das escolhas linguísticas, compatíveis com o nível vocabular da autora iniciante. 
No quarto e último parágrafo, além dos mecanismos já empregados em parágrafos anteriores, como a substituição das construções "à leitura provêm" por "ao tema advém" (L.1) e "pragmática" por "formal" (L. 5), os quais denotam respectivamente direcionamento ao tema leitura e incompreensão do termo pragmática por parte da autora, surge um trecho não plagiado. Tratase de trecho curto no qual a autora do artigo remete sua fala a tudo que foi argumentado anteriormente por meio de um mecanismo de coesão, apresentando o objetivo de seu artigo e o tipo de pesquisa (L. 7-9). Retoricamente, o texto discutido remete ao movimento de ocupação do nicho e funciona como uma estratégia para encerrar a discussão e avançar à seção seguinte.

Percebemos que a colaboradora foca nos aspectos formais, mas não apresenta competência em relação ao uso dos aspectos discursivos-enunciativos, pois não há um diálogo com outras vozes no texto, tampouco com a produção de um novo sentido, conforme Bakhtin (2003) define enunciação enquanto manifestação da autoria.

Fragmentos do parágrafo 4 também encontram-se disponíveis na página ${ }^{4}$ principal do Programa Nacional de incentivo à leitura (PROLER):

Figura 5: Texto disponível na página inicial do PROLER

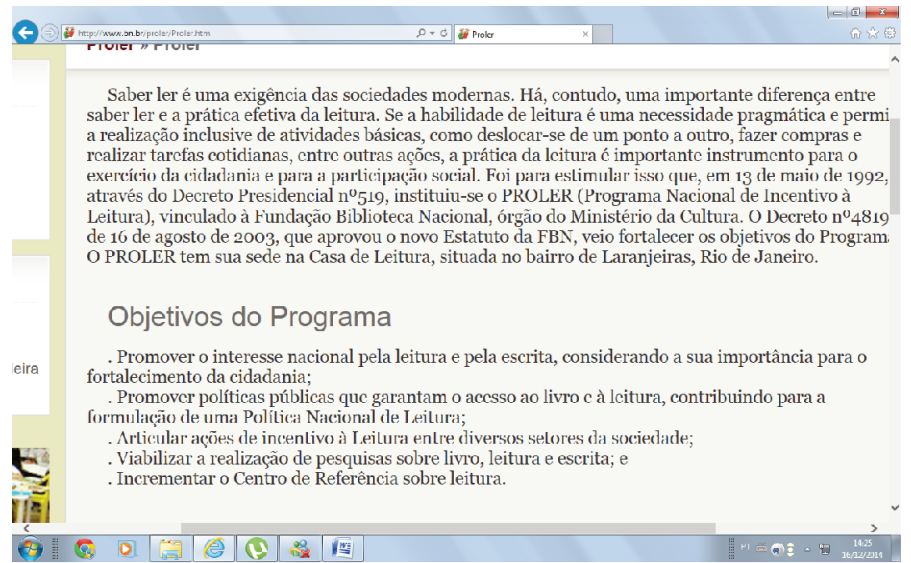

Fonte: Página virtual do Programa Nacional de incentivo à leitura (PROLER)

Constatada a prática do plágio na introdução do artigo investigado, buscamos identificar a presença de (possíveis) recursos linguísticos e discursivos empregados para introduzir marcas de autoria que 1) sinalizam a inserção da voz empírica do autor (BRONCKART 2012, p. 130 -131) nas introduções dos artigos acadêmicos, "voz" aqui compreendida, em um sentido estrito, enquanto aquela que profere o enunciado e/ou reproduz estruturas discursivas prototípicas; e que 2) denotam indícios de autoria no sentido mais amplo, enquanto Voz autoral que se insere no texto como legítimo membro da comunidade discursiva acadêmica - aquele que contextualiza, discute, problematiza, situa sua pesquisa, toma posição, avalia, comenta, interpreta e produz conhecimentos.

Nessa direção, segue a análise da marcação das vozes empíricas (sentido estrito) e das vozes com indício de autoria (sentido amplo) nas introduções dos artigos acadêmicos. Tendo em vista que nosso objetivo centrase na recuperação das marcas de autoria na produção fidedigna dos graduandos envolvidos na pesquisa, fazse importante ressaltar que a análise incidiu apenas nos trechos em que não foi identificada a prática do plágio. Desse modo, para a colaboradora A analisaremos apenas o excerto abaixo, uma vez que as demais partes da introdução são constituídas de cópia indevida.

Figura 6: Excerto autoral da colaboradora A

Diante deste contexto, este artigo tem como objetivo realizar uma reflexão a respeito da compreensão da leitura por alunos na academia, para isto, foi realizado uma pesquisa bibliografica.

Fonte: Introdução do artigo científico apresentado pela colaboradora A

A partir do excerto apresentado, notamos que se trata de um trecho de natureza descritiva no qual a colaboradora A realiza a apresentação do objetivo da pesquisa e destaca o aspecto metodológico do artigo por meio da própria voz ( $\mathrm{voz}$ do autor empírico), de modo não marcado em primeira pessoa.

As marcas linguísticas usadas pela colaboradora $\mathrm{A}$ para introduzir sua voz no texto foram o uso da terceira pessoa do singular do tempo presente - "tem" - seguido do verbo "foi", em terceira pessoa do tempo pretérito. Tais escolhas linguísticas denotam que o autor não chama para si as ações de delimitação dos objetivos e das escolhas metodológicas. Há, nesse caso, um distanciamento entre o autor e as ações do mesmo. Assim, 
embora de forma não marcada, e reconhecendo o caráter legítimo na produção das sequências destacadas, percebemos que elas não apresentam ações de tomada de posição, comentário, avaliação ou diálogo com outras vozes, constituindo-se apenas como uma sequência descritiva de aspectos organizacionais do trabalho. Desse modo, tomando como base o princípio dialógico da linguagem postulado por Bakhtin (2003), no qual a palavra/discurso é compreendida como uma memória semântico-social, um conjunto de vozes, o texto produzido pela colaboradora A não se constitui como uma enunciação dotada de uma nova produção de sentido, mas apenas como uma descrição dos aspectos organizacionais do artigo.

Essa dificuldade na produção do "novo sentido" pode ser fruto da complexidade do processo da escrita e da falta de um pleno domínio da temática por parte dos graduandos que, sem a competência necessária para fazer uso de sua voz nos textos, recorreram à prática do plágio.

\section{Produção II: colaboradora B}

A leitura do artigo científico da colaboradora B na íntegra permitiu-nos observar o emprego adequado da modalidade formal da língua, uso pertinente de recursos coesivos, linguagem clara e progressão textual, o que aponta para um bom domínio da língua e para a capacidade de elaborar a estrutura organizacional esperada para o gênero em foco.

A colaboradora B desenvolveu seu artigo em sete laudas e organizou seu texto a partir das seguintes partes constituintes: nome do autor, resumo, palavras-chave, introdução, fundamentação teórica, análise e discussão dos dados, considerações finais e referências.

Direcionando a análise para a introdução, centro desta investigação, a partir da observação da estrutura retórica, identificamos movimentos e passos prototípicos observados e propostos por Swales (1990). Apresentamos a seguir a introdução do artigo desenvolvido pela colaboradora $\mathrm{B}$, acompanhada da análise da sua estrutura retórica:

Figura 7: Estrutura retórica da introdução do artigo da colaboradora B

\section{INTRODUÇÃo}

O tema evasão escolar é um assunto abordado por vários autores e em várias obras. E pode-se se observar que é na educação de jovens e adultos que se verificam os números mais alarmantes deste fenômeno.Mas abordar a questão da evasão na educaçẳo de jovens e adultos no Brasil é sempre muito delicado, visto que envolve inúmeros condicionantes históricos, políticos, sociais e culturais que determinam esta realidade.

A evasão, especialmente no ensino noturno, nāo é um fato isolado, acontece cm escolas de grandes centros e em escolas de bairros mais periféricos, o que pode ser observado também nas escolas públicas de pequenas cidades do nordeste brasileiro como as de Equador RN.

Neste sentido/ podemos considerar a evasăo como uma situaçào problemática que produz uma série de consequências de ordem econômica $\mathrm{e}$ social para a localidade onde a escola está inserida.

Nesta perspectival faz-se necessário conhecer, e compreender as possiveis causas deste fenòmeno, tendo em vista as caracteristicas da modalidade e seu impacto social, econômico e cultural.

\section{M1: Estabelecer o território Passo 1: Fazer generalizaçoes \\ M2: Estabelecer o nincho Passo 1D: Continuar a tradiçao}

\section{M1: Estabelecer o} nincho

Passo 3: Revisar a literatura

M1: Estabelecer o nincho Passo 1: Estabelecer a importância da 
Diante deste contexto, este artigo tem como objetivo apresentar os principais motivos que levam os alunos a se evadirem da educação de jovens e adultos nas escolas públicas de Equador/RN.

O presente trabalho encontra-se dividido da seguinte forma: introduçăo, finais.

Quanto aos aspectos metodológicos optou-se por uma pesquisa qualitativa
descritiva fazendo-se uso de um questionário com perguntas abertas e fechadas que foi
aplicado junto aos sujeitos da pesquisa, quatro professoras que lecionam na educação de
jovens e adultos nas duas escolas campo do municipio de Equador/RN.
Para obter os resultados tomamos como categorias de análises a concepcão
docente sobre a evasão na EJA, a estrutura da escola e as suas implicações na
permanência dos alunos na EJA e a qualidade do material didático utilizado pelas
professoras.
fundamentaçâo teórica, análise e discussāo dos resultados e por fim as considerações

\section{pesquisa \\ M3: Ocupar o nincho \\ Passo 1A: Deliner \\ os objetivos}

\section{M3: Ocupar o nincho \\ Passo 3: Indicar a estrutura do artigo}

\section{M3: Ocupar o nincho Passo 1B: Apresentar a pesquisa}

\section{M3: Ocupar o nincho Passo 1B: Apresentar a pesquisa}

Fonte: Introdução do artigo científico apresentado pela colaboradora B

Destaca-se, na introdução em foco, a menção aos aspectos metodológicos e às categorias de análise. Um exame mais aprofundado do texto apresentado pela colaboradora B levou-nos à percepção de considerável

\section{2- UMA REFLEXÃO SOBRE A EVASÃo ESCOLAR NA EJA}

A Educação de Jovens e Adultos - EJA- no Brasil convive historicamente com um aito indice de evasão. Dos 8 milhōes de pessoas que frequentaram o curso até 2006, 42,7\% não chegaram a terminálo, segundo dados da Pesquisa Nacional por Amostra de Domicilios (Pnad) de 2007.

A evasaso, especialmente no ensino noturno, é uma realidade de grande parte das escolas, nåo é um fato isolado, acontece em escolas de grandes centros e também nas que se localizam em bairros mais afastados. $O$ que pode ser observado na E.E. Maria Meriam dos Santos Cordeiro Fernandes, onde, segundo dados estatisticos do ano letivo de 2010, evidenciou-se um indice de $43 \%$ de evasão no segundo segmento da EJA. Contudo, nāo se pode aceitar passivamente esta realidade, ou simplesmente ignorá-la.

1 - tema "evasão escolar" é um assunto abordado por vários autores e em várias obras. E pode-se observar que é na EJA que se vê os nûmeros mais Jiarmantes desse fenomenoq Nesse sentido, e preciso considerar que a evasão escolar é uma situaçăo problemática, que se prođuz por uma série de determinantes. Abordar a questão da evasáo na Educaçåo de Jovens e Adultos á sempre muito delicado, visto que, şa inùmeros condicionantes históricos, politicos. sociais e culturais que determinam essa realidade. No entanto, pode-se perceber que este é um dos grandes desafios pertinentes ao sistema educacional brasileiro, mais especificamente à escola pública.

Nessa perspectiva, faz-se necessário conhecer e compreender as possiveis

5 usas desse fenômeno, tendo em vista as caracteristicas dess modalidade de ensino e seu impacto social e econômico. É preciso conhecer a realidade dos individuos inseridos nessa problemática, bem como os fatores socioeconómicos e culturais que contribuem para que os alunos se afastem da escola. E ainda, é necessario conhecer os fatores didáticos e pedagógicos que porventura também possam estar colaborando para a manutençào desse quadro de alto índice de evasăo escolar. No entanto, é importante evidenciar que a EjA é uma educaçăo possivel e capaz de mudar significativamente o futuro de uma pessoa, permitindo-the reescrever sua história de vida. semelhança com um artigo, também, de circulação eletrônica. ${ }^{5}$ A seguir, o texto original (em cor azul), sendo comparado ao texto apresentado pela colaboradora $\mathrm{B}$ (em cor de rosa):

Figura 8: Texto original $\mathrm{x}$ introdução artigo científico da colaboradora B

\section{INTropuç̃o}

10 temu evaslo escolat é um assunto aborlado por virtios autores e em vírias obras. E. pode-se se ohservar que é na educachlo de jovens e adultios que se verificam os

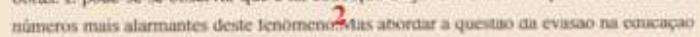
de joverns e adultos no Bravil é sempre muito delicado, visto que envolve inâmeros condicionumtes hisqórioxs, politicos, sociais e cultunis que determinum esta realidade

$3 \wedge$ evasio, especialmente no ensino noturna, nào é um fato isolado, acontece em escolas de geninder centros $\mathrm{e} \mathrm{cm}$ ceocolas de hairtos mais periéricos, o que pode ser othervido também nas escolas püblicas de pequenan cidades do nordeste brasileiro como as de Equabor /RN4 Neste sentido/ podemos considerar a cvasibo como uma situaglbo problemítica que produe uma série de consequéncias de ardem econòmica c social para a localidade onde a escola esta inserid $\mathbf{5}$ Nesta perspectiva|fiz-se nocessitio

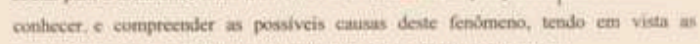
caracteristicas du modalidade e scu impacto social, económico e cultural.

Diante deste contexto, este artipo tem como objetivo apresentar on principais motivos que levam os afunos a se evadirem da educasło de jovens e adultos nas escolas públicas de Equador /RN.

b

presente tratulho encontra-se dividido da seguinte forma introdaçion, fundamentacho teórica, analise e discussio dos resultados e por fim as considenaçnos finuis.

Quanto ass aspectos metodologicos optou-se por uma pesquiva qualitativa decritiva fivendo-s $x$ uso de um questionitio com perguntas abertis e fechadis que foi aplicado junto aos srjeitos da pesquiks, quatro professoras que leciontam na educaclo de jovens c adultios nas duas escolas campo do municipio de Equador/RN.

Para obter os resultados tomamos como categarias de analisei a concepclio docente sobre a evasấo na EA, a estrutura da escola $\mathrm{C}$ as sums implicapiles na permanéncia dos alunos na ESA e a qualidade do material didatioo utilizado pela professoras.

Fonte: Introdução do artigo científico apresentado pela colaboradora B; Texto original (ALVES, 2011) 
Comparando o texto original com o texto copiado, verifica-se que houve uma preocupação com a reorganização da ordem do plano argumentativo. É interessante notar que o fragmento selecionado para compor o parágrafo inicial constitui-se como um tópico mais geral - assim como uma das possibilidades de início do texto, visto pela colaboradora $\mathrm{B}$ nas aulas do componente curricular APTA. Percebe-se que os movimentos de estabelecimento do território e estabelecimento de nicho são copiados (parágrafos iniciais: 1 e 2), enquanto que o movimento de ocupação de nicho (parágrafos finais: 3,4,5 e 6) foi desenvolvido. Verifica-se ainda que, mesmo copiando partes da introdução, a colaboradora demonstra esforço em organizá-la ao seu modo, uma vez que reestrutura a disposição dos parágrafos da introdução. A seguir, expomos o texto apresentado por B (em cor de rosa) justaposto aos textos originais (em cor azul), enfatizando mecanismos linguísticos e organizacionais empregados pela colaboradora B na tessitura da sua introdução, segundo legenda da tabela 2 - Mecanismos usados na tessitura da introdução -, abaixo retomada:

Tabela 2: Mecanismos usados na tessitura da introdução

Apagamento de termos e/ou ideias
Substituição de termos/ elementos coesivos e ajustes
Inclusão de termos
Trechos autorais
Posição do apagamento

Fonte: Elaborada pela autora (2015)

Figura 9: Autoria x plágio: Introdução artigo científico da colaboradora B

\section{INTRODUÇ̃̃o}

O temanevasão escolan é um assunto abordado por vários autores $\mathrm{c}$ em várias obras. E pode-se se observar que é na educacão de jovens e adultos que se verificam os números mais alarmantes deste fenômeno.Mas abordar a questão da evasăo na educaçăo de jovens e adultos no Brasil é sempre muito delicado, visto que Łenvolve inúmeros condicionantes históricos, politicos, sociais e culturais que determinam esta realidade. ?

O tema "evasão escolar" é um assunto abordado por vários autores e em várias obras. E pode-se observar que é na EJA que se vê os números mais alarmantes desse fenômeno. (...)

Abordar a questão da evasão na Educação de Jovens e Adultos é sempre muito delicado, visto que, são inúmeros condicionantes históricos, politicos, sociais e culturais que determinam essa realidade. No entanto, pode-se perceber que este é um dos grandes desafios pertinentes ao sistema educacional brasileiro, mais especificamente à escola pública.
A evasão, especialmente no ensino notumo, Inão é um fato isolado, acontece em escolas de grandes centros e em escolas de bairros mais periféricos, o que pode ser observado também nas escolas públicas de pequenas cidades do nordeste brasileiro como as de Equador /RN.INeste sentido/podemos considerar a evasão como uma situaçấo problemática queıproduz uma série de consequências de ordem econòmica c social para a localidade onde a escola está inserida. Nesta perspectival faz-se necessário conhecer_. c compreender as possiveis causas deste fenômeno, tendo em vista as caracteristicas da modalidade e seu impacto social,"econòmico e cultural.

A evasão, especialmente no ensino noturno, é uma realidade de grande parte das escolas, não é um fato isolado, acontece em escolas de grandes centros e também nas que se localizam em bairros mais afastados. O que pode ser observado na E.E. Maria Meriam dos Santos Cordeiro Fernandes, onde, segundo dados estatísticos do ano letivo de 2010, evidenciou-se um indice de $43 \%$ de evasão no segundo segmento da EJA. Contudo, não se pode aceitar passivamente esta realidade, ou simplesmente ianorá-la. Nesse sentido, é preciso considerar que a evasão escolar é uma situação problemática, que se produz por uma série de determinantes.

Nessa perspectiva, faz-se necessário conhecer e compreender as possiveis causas desse fenômeno, tendo em vista as caracteristicas dessa modalidade de ensino e seu impacto social e econômico. É preciso conhecer a realidade dos individuos inseridos nessa problemática, bem como os fatores socioeconômicos e culturais que contribuem para que os alunos se afastem da escola. E ainda. é necessário conhecer os fatores

Diante deste contexto, este artigo tem como objetivo apresentar os principais motivos que levam os alunos a se evadirem da educação de jovens e adultos nas escolas públicas de Equador/RN.

O presente trabalho encontra-se dividido da seguinte forma: introdução, fundamentação teórica, análise e discussão dos resultados e por fim as considerações finais.

Quanto aos aspectos metodológicos optou-se por uma pesquisa qualitativa descritiva fazendo-se uso de um questionário com perguntas abertas e fechadas que foi aplicado junto aos sujeitos da pesquisa, quatro professoras que lecionam na educação de jovens e adultos nas duas escolas campo do município de Equador/RN.

Para obter os resultados tomamos como categorias de análises a concepç̃o docente sobre a evasão na EJA, a estrutura da escola e as suas implicações na permanência dos alunos na EJA e a qualidade do material didático utilizado pelas professoras.

Fonte: Introdução do artigo científico apresentado pela colaboradora B

No parágrafo inicial, percebemos mecanismos linguísticos de apagamento de aspas (L.1), vírgula (L.4) e fragmentos de texto (L. 5), substituição de termos como "EJA" por "educação de jovens e adultos" (L. 2), emprego da forma verbal " $v \hat{e}$ " por "verificam" (L. 2) e de são por envolve (L.4).

Modificações com mais destaque podem ser vistas no parágrafo dois, no qual fica mais evidente a presença dos mecanismos de apagamento, substituição e, até mesmo, inclusão de termos. Já os parágrafos posteriores apresentam uma organização diferenciada.

A partir do terceiro parágrafo, observamos indícios de autoria da colaboradora $\mathrm{B}$, com o intuito de 
apresentar objetivos (parágrafo 3), organização do trabalho (parágrafo 4), aspectos metodológicos (parágrafo 5) e categorias de análise (Parágrafo 6).

Assim como a colaboradora A, a colaboradora B também demonstrou um cuidado com a tessitura do seu texto, notadamente quanto à estrutura retórica organizacional. Os mecanismos linguísticos empregados para disfarce também direcionam para suposições já mencionadas, como adequação ao nível vocabular e a adequação à temática do artigo.

Com relação à observação das marcas de autoria, verificamos que não houve uma mobilização de aspectos discursivos-enunciativos de modo que fosse gerada uma nova produção de sentido e entrelaçamento de vozes, conforme propõe Bakhtin (2003) em sua noção de autoria. A colaboradora B apresenta boa parte do seu texto constituído de cópia, com exceção dos parágrafos apresentados abaixo:

Figura 10: Excertos autorais da colaboradora B

Diante deste contexto, este artigo tem como objetivo apresentar os principais motivos que levam os alunos a se evadirem da educação de jovens e adultos nas escolas públicas de Equador/RN.

D

O presente trabalho encontra-se dividido da seguinte forma: introdução, fundamentação teórica, análise e discussão dos resultados e por fim as considerações finais.

Quanto aos aspectos metodológicos optou-se por uma pesquisa qualitativa descritiva fazendo-se uso de um questionário com perguntas abertas e fechadas que foi aplicado junto aos sujeitos da pesquisa, quatro professoras que lecionam na educação de jovens e adultos nas duas escolas campo do município de Equador/RN.

Para obter os resultados tomamos como categorias de análises a concepção docente sobre a evasão na EJA, a estrutura da escola e as suas implicações na permanência dos alunos na EJA e a qualidade do material didático utilizado pelas professoras.

Fonte: Introdução do artigo científico apresentado pela colaboradora B

Os trechos analisados dão conta de que a voz enunciada é a voz da própria autora do texto. No entanto, também apontam que a colaboradora $\mathrm{B}$ os desenvolve com o intuito de apontar aspectos composicionais da introdução do artigo - como apresentação dos objetivos, descrição da organização do trabalho, descrição de aspectos metodológicos e categorias de análise.

É possível perceber fortemente a natureza descritiva dos parágrafos e a tentativa de inserção do sujeito como agente nas ações: há uma oscilação entre emprego de verbos pessoais - primeira e terceira pessoa, "tomamos", "visa", e verbos impessoais, tais como "encontra-se" e "optou-se". O emprego do verbo "tomamos" na primeira pessoa do plural denota o comprometimento direto do autor com o seu enunciado.

Assim, embora também reconhecendo a voz do autor na constituição dos excertos, ou seja, enquanto $v o z$ empírica que enuncia, ainda não se pode falar em presença de autoria no que concerne à produção do novo sentido, uma vez que não aparece uma produção nova e autônoma (BAKHTIN, 2003). Na perspectiva dos estudos enunciativos, a produção autoral sempre cria algo que não existia antes dele, absolutamente novo e singular (BAKHTIN, 2003). Assim, no tocante à produção da colaboradora $\mathrm{B}$, podemos falar apenas em reprodução de aspectos formais e organizacionais da introdução.

\section{O que dizem as colaboradoras acerca das suas dificuldades}

Também em consonância com a perspectiva dos Novos Estudos dos Letramentos, interessou-nos a apreensão do ponto de vista dos sujeitos envolvidos no processo de escrita - _enquanto ferramenta valiosa na construção e compreensão do processo ensino-aprendizagem. Desse modo, importou-nos ouvir os colaboradores envolvidos na pesquisa acerca dos seus processos de escrita. Seguem, na tabela 3, as avaliações das colaboradoras realizadas em resposta ao questionário aplicado em momento posterior à elaboração do artigo científico a respeito das suas dificuldades na elaboração dos mesmos:

Tabela 3: Dificuldades na elaboração dos artigos científicos

\begin{tabular}{l|l}
$\begin{array}{l}\text { Carga horária } \\
\text { insuficiente }\end{array}$ & $\begin{array}{l}\text { "o tempo para leitura (do material } \\
\text { teórico) foi pouco, devido a quantidade } \\
\text { de feriados que tivemos nos dias de } \\
\text { aula desta disciplina." (Colaboradora } \\
\text { A) }\end{array}$ \\
\hline $\begin{array}{l}\text { Falta material } \\
\text { teórico }\end{array}$ & $\begin{array}{l}\text { "senti dificuldades em desenvolver o } \\
\text { referencial teórico, eu não dispunha de } \\
\text { muito material relacionado ao tema." } \\
\text { (Colaboradora A) }\end{array}$
\end{tabular}




\begin{tabular}{l|l}
$\begin{array}{l}\text { Conhecimento } \\
\text { insuficiente do } \\
\text { gênero }\end{array}$ & $\begin{array}{l}\text { "dificuldade de organizar as ideias na } \\
\text { fundamentação teórica." (Colabora- } \\
\text { dora B). }\end{array}$ \\
& "dificuldade na escolha das categorias \\
& de análise dos dados"; (Colaboradora \\
B). & "dificuldade em demonstrar o ponto \\
de vista na análise dos dados"; (Colab- \\
oradora B).
\end{tabular}

Dados obtidos a partir das repostas aos questionários aplicados em fase final da pesquisa

As respostas apontaram dificuldades de diferentes naturezas como: I) fator tempo - carga horária insuficiente - para leitura do material teórico a fim de fundamentar os artigos; II) dificuldades na organização das ideias, na criação de categorias de análise e na demonstração de ponto de vista. Essas dificuldades apontam para a carência do letramento acadêmico advindo das poucas práticas com a escrita e com o discurso científico. Outra constatação importante é quanto à abertura possibilitada pelo professor da disciplina em relação à diversidade de temáticas a serem abordadas no âmbito dos estudos da linguagem, o que, ao invés de oportunizar a liberdade de escolha de um dos temas sugeridos, causou indecisão e dificuldade, por parte de alguns alunos, na escolha do tema. Prova disso é que alguns deles mudaram a temática do artigo a ser produzido, apenas quinze dias antes da entrega da versão final do mesmo.

\section{Considerações finais}

A análise dos dados evidenciou que as colaboradoras da pesquisa recorreram à prática da cópia indevida (plágio) em função de uma série de dificuldades, sobretudo, na construção do discurso científico e no desenvolvimento de uma linha argumentativa ou expositiva de forma clara e autônoma; ou seja, não se assumiram, efetivamente, como sujeitos dos seus discursos. Ao considerarmos a complexidade do processo de escrita de um artigo científico, especialmente quando produzidos por alunos do segundo período de um curso de graduação, percebemos que diversos fatores concorrem para a constatação a que chegamos.

O primeiro deles, talvez o mais importante para o distanciamento das colaboradoras em relação ao próprio texto, é a falta do domínio da temática, advinda, certamente, da falta do conhecimento do assunto a ser tratado e do tempo insuficiente para a leitura do referencial teórico selecionado para a escrita do artigo, conforme explicitou a colaboradora $\mathrm{A}$, em um de seus depoimentos sobre as principais dificuldades em termos de escrita.

O segundo fator, relacionado à questão do letramento acadêmico, diz respeito à falta de familiaridade com os gêneros acadêmicos e da inexperiência em relação à produção de artigos científicos, pois embora o histórico de letramento das colaboradoras tenha apontado uma relação de proximidade com a escrita, o artigo científico é um texto específico do contexto universitário, para o qual são exigidas novas maneiras de compreender, interpretar e organizar o conhecimento (Cf. LEA; STREET, 1998, p. 158). A não consolidação da apropriação do gênero artigo científico também fica salientada na avaliação da colaboradora B quanto às dificuldades encontradas para elaborar o seu artigo, apontando a sua dificuldade na organização das ideias, na criação de categorias de análise e na demonstração do ponto de um vista. Tal fato ratifica a constatação de que as colaboradoras ainda estavam em processo de construção dos conhecimentos da forma, do discurso e dos modos próprios do dizer e do fazer científico.

Outros fatores que devem ser considerados para a ocorrência do plágio na produção da escrita acadêmica são a cobrança da produção de textos acadêmicos a alunos iniciantes, bem como a reprodução da prática de atividade de cópia realizada durante toda a educação básica. Além disso, há a necessidade de se discutir, no âmbito acadêmico, o fenômeno do plágio do ponto de vista ético, pois não há segurança de que este seja um conceito claro para o aluno. As introduções analisadas revelam que as colaboradoras apresentam um cuidado com a tessitura dos seus textos, fazendo uso de mecanismos linguísticos e estruturais (apagamento de termos ou ideias; substituição de termos ou elementos coesivos; inclusão de termos; e indicação da posição do apagamento), possivelmente, para adequação ao nível vocabular e à temática do artigo, o que pode ser interpretado, inclusive, como tentativa de manipulação.

Diante de toda a discussão apresentada, compreendemos que há a necessidade de práticas de ensino de 
escrita na escola e na universidade que favoreçam aos alunos a condição necessária para se produzir gêneros acadêmicos atentos aos aspectos formais e discursivos -enunciativos, bem como de uma ampla discussão acerca do conceito de plágio na academia, a fim de que seja possível uma escrita conforme a perspectiva bakhtiniana, a qual pressupõe uma nova produção de sentido a partir do caráter criativamente produtivo e autônomo do autor para a tomada de posições, discussão, problematização, articulação do discurso próprio com o discurso do outro e inserção da voz do autor na construção e na constituição do texto com a intenção de produzir interpretações e conhecimentos autênticos.

A presente pesquisa, embora favoreça aos professores e alunos da esfera acadêmica uma reflexão relevante sobre o letramento acadêmico, a autoria e o fenômeno do plágio, não esgota a reflexão sobre a referida temática em si mesma e, assim, apresenta-se como uma abertura para investigações futuras que possam desvendar, de forma bem mais precisa, questões como: as causas do plágio, as dificuldades que os alunos enfrentam na tarefa da escrita acadêmica, como também a metodologia voltada ao ensino de escrita na academia.

\section{Notas}

1. O modelo CARS não foi criado aleatoriamente. Resultou de um estudo das regularidades, no qual Swales (1990) observou 48 artigos científicos seguidos de mais 110 artigos de diferentes áreas do conhecimento.

2. Apresentaremos apenas a análise relativa a dois dos três artigos analisados originalmente, em virtude da necessidade de recorte dos dados para a escrita deste trabalho. Para ter acesso a análise integral, consultar Moura (2015).

3. Artigo publicado na Revista Lugares de Educação, Bananeiras/PB, v. 1, n. 2, p. 325-346, jul.-dez. 2011 ISSN 2237-1451. Disponível em http://periodicos. ufpb.br/ojs2/index.php/rle.

4. Disponível: <http://www.bn.br/proler/Proler.htm> Acesso em 16 de Dez de 2014 às 13h26min.

5. O referido artigo é de autoria de Guiovane Alves, intitulado "A evasão escolar na EJA: Uma realidade da escola estadual Maria Merian dos Santos Cordeiro Fernandes" disponível em http://www. recantodasletras.com.br/artigos/3302393>.

\section{Referências}

ALVES, GUIOVANE. A evasão escolar na EJA: Uma realidade da escola estadual Maria Merian dos Santos Cordeiro Fernandes. Disponível em: http://www. recantodasletras.com.br/artigos/3302393 acesso em 23 de setembro de 2014.

BAKHTIN, Mikhail. Estética da criação verbal. Trad. Paulo Bezerra. São Paulo: Martins Fontes, 2003 [1979]

BEZERRA, Benedito Gomes. Letramentos acadêmicos na perspectiva dos gêneros textuais. Fórum Linguístico, v. 9, n. 4, p. 247-258, out/dez. 2012.

BIASI-RODRIGUES, B.; ARAÚJO, J. C.; SOUZA, C. S. T. Análise de gêneros na abordagem de Swales: princípios teóricos e metodológicos. In: (Org.). Gêneros textuais e comunidades discursivas: um diálogo com John Swales. Belo Horizonte: Autêntica, 2009. p. 17-32. (Leitura, Escrita e Oralidade).

BRONCKART, Jean-Paul. Atividade de linguagem, textos e discursos: por um interacionismo sóciodiscursivo. São Paulo: EDUC, 2012.

COSTA, Adriano Ribeiro. Mecanismos Enunciativos: Análise Das Vozes E Modalizações Em Artigos Científicos. Rios Eletrônica - Revista Científica da FASETE, ano 6, n. 6. Dezembro de 2012. 28-39.

DELCAMBRE, Isabelle. Formas diversas de articulação entre o discurso de outrem e o discurso próprio: análises de comentários de textos teóricos. In: Letramento e formação universitária: formar para a escrita e pela escrita. Fanny Rinck, Françoise Boch, Juliana Alves Assis, (Org.). - Campinas, SP: Mercado das Letras, 2015. (Série Ideias Sobre Linguagem).163-204.

FIGUEIREDO, Débora de C.; BONINI, Adair. Práticas discursivas e ensino do texto acadêmico: concepções de alunos de mestrado sobre a escrita. Linguagem em (Dis)curso, Tubarão, v. 6, n. 3, p. 413-446, set./dez. 2006.

FONSECA, Randal. Expropriação de propriedade intelectual. Disponível em: <http://www.historia ehistoria.com.br/materia.cfm? $\mathrm{tb}=$ newsletter\&id $=3>$. Acesso em: 13 mai. 2015.

LEA, Mary R.; STREET Brian V. Student writing in higher education: an academic literacies approach. Studies in higher education. v.23, n. 2, p 157-172, jun. 1998.

LUDKE, M.; ANDRÉ, M. E. D. A. - Pesquisa em educação: abordagens qualitativas. São Paulo, E.P.U., 1986. 99p.

MACHADO, Anna Rachel (coord.). Planejar gêneros acadêmicos. São Paulo: Parábola Editorial, 2004. vol. 3. (Coleção Leitura e produção de textos técnicos e acadêmicos). 
MARINHO, Marildes. A escrita nas práticas de letramento acadêmico. Belo Horizonte, Revista Brasileira de Linguistica Aplicada, v. 10, n. 2, 2010. p. 363-386.

MOTTA-ROTH, Désirée; HENDGES, Graciela Rabuske. Produção textual na universidade. São Paulo: Parábola Editorial, 2010.

MOURA, Lucielma de Oliveira Batista Magalhães de. O trabalho com a produção do artigo científico: implicações na construção do letramento acadêmico e da autoria. 2015. 135f. Dissertação de Mestrado.Universidade Federal de Campina Grande - UFCG. Campina grande, Paraíba, 2015.

. Análise crítica de gêneros: contribuições para o ensino e a pesquisa de linguagem. DELTA [online]. v. 24, n.2, p. 341-383, 2008. Disponível em: <http:// dx.doi.org/10.1590/S0102-44502008000200007> . Acesso em: 26 de junho de 2014.

OLIVEIRA, Elaine Feitoza. Letramento acadêmico: concepções divergentes sobre o gênero resenha crítica. 2010. 270f. Dissertação de Mestrado. Campinas. - Universidade Estadual de Campinas Unicamp. Campinas, São Paulo. 2010. Disponível em: < http://www.bibliotecadigital.unicamp.br/ document/? code $=000785488>$ Acesso em: 30 mar. 2014.

SANTOS, Eliete Correia dos. Uma proposta dialógica de ensino de gêneros acadêmicos: nas fronteiras do projeto SESA. 2013. 418f. Tese (Doutorado em Linguística) - Programa de Pós-Graduação em Linguística, Universidade Federal da Paraíba, João Pessoa, 2013.

SILVA, Elizabeth Maria da (Org.). Professora, como é que se faz?. Campina Grande: Bagagem, 2012.

Os mistérios que envolvem a escrita acadêmica. In: IV Simpósio Internacional de Ensino de Língua Portuguesa, 2014, Uberlândia. Anais do IV Simpósio Internacional de Ensino de Língua Portuguesa. Uberlândia: EDUFU, 2014. v. 3. p. 1-9.

SILVA, Obdália Santana Ferraz. Entre o plágio e a autoria: qual o papel da universidade? Revista Brasileira de Educação. V. 13, nº 38, maio/ago 2008.

SOBRAL, Adail. Autoria e estilo. In: Do dialogismo ao gênero: as bases do pensamento do círculo de Bakhtin. Campinas: Mercado das Letras, 2009. Série Ideias sobre linguagem, p. 61-71.

SWALES, John M. Genre analysis: English in academic and researching setting. Cambridge: Cambridge University Press, 1990.
. Sobre modelos de análise do discurso. In: Gêneros textuais e comunidades discursivas: um diálogo com John Swales. BIASI-RODRIGUES, B.; ARAÚJO, J. C.; SOUZA, C. S. T. (Org.). Belo Horizonte: Autêntica, 2009. 33-46.

TOURINHO, Cleber. Refletindo sobre a dificuldade de leitura em alunos do ensino superior: "deficiência" ou simples falta de hábito Revista Lugares de Educação, Bananeiras/PB, v. 1, n. 2, p. 325-346, jul.-dez. 2011 ISSN 2237-1451. Disponível em http://periodicos. ufpb.br/ojs2/index.php/rle.

Recebido em: 29/02/2016 Aceito em: 11/07/2016 